\title{
sciendo
}

\section{Seasonal adjustment of tourism data for Romania using JDemetra+}

\author{
Tudorel ANDREI \\ The Bucharest University of Economic Studies, Bucharest, Romania \\ andrei.tudorel@csie.ase.ro \\ Andreea MIRICĂ \\ The Bucharest University of Economic Studies, Bucharest, Romania \\ miricaandreea89@gmail.com \\ Ionela-Roxana GLĂVAN \\ The Bucharest University of Economic Studies, Bucharest, Romania \\ roxana.glavan10@yahoo.com \\ Georgiana Andreea FERARIU \\ The Bucharest University of Economic Studies, Bucharest, Romania \\ ferariugeorgiana@yahoo.com \\ Ioan Mincu RADULESCU-GEORGE \\ The Bucharest University of Economic Studies, Bucharest, Romania \\ mincu.ioan@yahoo.com
}

\begin{abstract}
Tourism statistic data can is an important source for measuring touristic patterns. As this area became more and more dynamic with the globalisation process, business owners, business analysts, policy makers as well as researchers are highly interested in having accurate, reliable and diverse data on tourism in order to perform analysis. Seasonal adjustment presents a real challenge for all researchers that operate with data sources from tourism sector. Usage of time series presents both opportunities and may contribute to improvement of forecasting touristic specifics relaying on demand and supply side of seasonality phenomenon. However, seasonally adjusted data is viewed as major challenge for businesses operating in the touristic sector. The present research focuses on a methodology that includes monthly tourist data arrivals in Romania. The seasonal adjustment process is performed with JDemetra+, both considering and excluding calendar effect. JDemetra+ is the software officially recommended by Eurostat for seasonal adjustment, being tested extensively by many experts in the field, from various organisations. The seasonal adjustment process pointed out promising and qualitative results, as no Easter and trading days effect were present, suggesting effect of calendar omission from the process. Our obtained results showed up significantly better results for the 5 years series span. The similarities for TRAMO-SEATS and X13 obtained results indicate that in order to minimise sensitivity and choose correctly between the two packages, further revisions may be considered. This paper provides an excellent starting point for further research aimed at improving data on tourism. The methodology tested in this research can be further improved and applied on other data regarding tourism.
\end{abstract}

Keywords: Romania, tourism seasonality, JDemetra+, tourism policy, statistics measurements 


\section{Introduction}

The importance of tourism statistics is closely linked to the existence of modern software tools that analyses the touristic characteristics changes over specific time frames. Thus, the relevance of these statistics resides in their usage to follow-up if the implemented policies in this domain of activity properly address the strategic country objectives. In order to have a positive gain from touristic activity, a country needs to address specific policies and to efficiently invest based on objective criteria that really matter. These objective criteria must be periodically reviewed and aligned with the regional development and closely linked with their impact in the overall country economy (Panyik \& Zaharia, 2014).

From business perspective the touristic data are of great importance. This information brings added value to the existing actors in this economic field and also supports them to become more competitive in the global touristic market. Bringing new products that increase the overall market share of the touristic business is based upon the elaboration of good strategies that rely heavily on statistical data usage.

Such strategies that are based upon statistical data may also improve management decisions in order to elaborate better directives to achieve expected results (Wöber, 2000). The success or the in-success of a directive may be followed-up by the collected statistical results over a time window. For touristic business these statistics determine the quality of the management decisions.

National tourism policies often rely on the actuality of the statistical data sources. A recent paper (Eurostat, 2017) recognised the importance of exploring big data sources. According to Xin Yang et al. (2015) co-integration of the relationship between search engine query data and the volume of tourist visitors on regional level significantly decreases forecasting errors by including seasonality adjustment framework. Data such as the number of domestic tourists, the demographics on tourists coming in and going out of the country are resources that bring information for the elaboration of strategies, policies and national programs in field of tourism. Moreover it may be concluded a specific pattern that indicate the places that are most often visited by tourists, the types of accommodation and foods. Furthermore, based on sufficient statistical data it is possible even to predict the expenses model for the tourists.

All the above mentioned, highlight that tourism statistics data is an important source of information for all countries. Tourism plays an important role each year on the economy of each country. Thus, of great importance for Romania is to collect tourism statistics (Danubianu et al., 2009) and based upon them it is a mandatory to establish national objectives and policies to improve the growth of this economic field.

The datasets that are used in current research originate from National Institute of Statistics of Romania and Eurostat databases. The time chosen for them starts in 2010 until 2018 with monthly granularity.

The aim of this paper is to explore the possibility to seasonally adjust tourism data for Romania in other to assess the quality that such series might have. Such constructs offer better clarity to all insights in field of tourism and give new processing tools to all relevant actors in this field. Using such data, business owners, business analysts, policy makers as well

as researchers can anticipate better the evolution of this sector. This is an essential element for better planning especially in such a dynamic filed like tourism. 


\section{Literature review}

From a statistical context, tourism is defined as people's activity of visiting destinations outside the engagement in their usual behavioural activities, for less than one year. The indicator of tourist arrivals is commonly used by mainstream researchers in order to perform time series analysis. An important aspect for tourism research area is identified by Rodrigues and Gouveia (2004) as being the impact of seasonality usage.

Seasonality, according to Butler (1994) is viewed as "a temporal imbalance in the phenomenon of tourism, may be expressed in terms of dimensions of such elements as numbers of visitors, expenditure of visitors, traffic on highways and other forms of transportation, employment, and admissions to attractions". Tourism as well as other economic branches such as agriculture and manufacturing share high similarity in respect to temporal variation that generate seasonal and periodic distortions in both production and consumption (Kusnets, 1933).

Generally, Hylleberg (1992) highlighted the root cause of seasonality and referred to it as being "systematic, although not necessary regular, intra-year movement caused by changes in weather, the calendar, and timing of decisions, directly or indirectly through the production and consumption decisions made by agents of the economy". Consequently, based on this assumption Butler (2001) considers this phenomenon a negative aspect rather than positive for tourism forecasting.

In certain circumstances such touristic periodic events create a positive economic impact to both cities and rural destinations. Nevertheless, seasonality can be seen as benefit or as a problem depending on the seats at the economic table. Positive aspects of seasonality are often considered a leap advantage in the field of research of events and festivals planning, mainly as it focuses more on the demand rather than the supply side of the phenomena, as the last is being considered by Baum and Hagen (1999) affected by behaviour.

However, seasonality adjustment is viewed as major challenge for businesses operating in the touristic sector. This originates from the difficulties in predicting seasonal tourism income in regions characterized by an increased level of changes in seasonal patterns. In their works Butler (2001) and Hinch and Jackson (2000) highlighted that such difficulties are translated to lower level of access to investments and higher risk of operations for the business. Furthermore, Stefano de Cantis et al. (2011) emphasise on the seasonality and its application and measurements of pattern and amplitude for investigating tourism bed occupancy.

The added value that is brought up by the changing of seasonality in order to minimize these operating risks is also flagged in researches conducted by Pegg et al. (2012). In their work such usage is associated with a lower chance to estimate peak periods with insufficient employed staff. From business perspective seasonality adjustment usage offers better forecasting performance to increase service quality and tourist satisfaction in peak periods. The effect of seasonality treatment on time-series models is also considered in forecasting seasonal tourist demand in order to improve overall accuracy according to Shujie Shen et al. (2009).

Europe became multidimensional and one of its priorities is creating the contextual framework for sustainable tourism, for "Making Europe 'the world's number 1 destination" (European Committee of the Regions, 2017 https://cor.europa.eu/en/news/Pages/ Europes-leaders-set-out-vision-for-sustainable-tourism-to-drive-growth-and-create-jobs. aspx). Tourism sector has a potential impact role at territorial level and can sustain local and 
regional economic development as well as cooperation (European Committee of the Regions, 2016). In this respect, in a joint open letter of the European Committee of the Regions, the European Parliament, the NECSTouR and the European Travel Commission, addressed to Jean-Claude Juncker, President of the European Commission, it is pointed out that tourism is a very important sector from an economic and social perspective as "not only generates 10\% of the EU's GDP and provides employment for up to 15\% of the population (including a large proportion of young people and women), it also helps integrate low-skilled Europeans and migrants to the labour market" (https://cor.europa.eu/Documents/ Migrated/Events/Revision\%20of\%20the\%20EU\%202010\%20Tourism\%20Strategy\%20\%

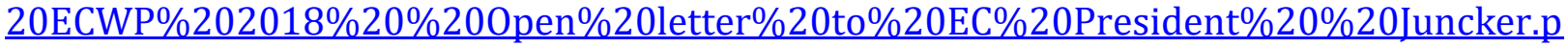
df). As we mentioned in the introduction, an overall policy, based on usage of high quality statistical data, is needed to drive growth in Romania's tourism sector.

\section{Methodology}

For the purpose of this paper, monthly data on arrivals of tourists accommodated in the structure of tourists reception at national level will be used. To our appreciation, based on the literature review performed above, this is one of the most relevant time series for business owners. These data are provided by the National Institute of statistics and are available in the Tempo Database for January 2010 until December 2018.

In order to seasonally adjust this time series the methodology proposed by Mirică et al. (2016) will be used. This methodology was conceived for quarterly time series, but as Toma et al. (2018) showed, it works for monthly data also. As some slight adjustments had to be made to this methodology so that it suits this particular case, we will briefly describe it in the following paragraphs.

In order to compute the seasonally adjusted series JDemetra+ 2.2.0 was used, as this is a very user friendly tool with many functionalities for seasonal adjustment (Grudkowska, 2015). According to Grudkowska (2015), it incorporates ready-to use tools for the most extensively used seasonal adjustment packages: TRAMO SEATS (model based package developed within the Bank of Spain by Victor Gómez and Agustín Maravall) and X-12ARIMA/X-13ARIMA-SEATS (filter based package, developed within the U.S. Census Bureau). The program suffered major improvements over time: compared to its predecessor, Demetra+, it has a richer and easier to use graphical interface; many plugins were developed since its' creation due to its' high flexibility; incorporation of Julian Easter ReGressors within the predefined calendar (Grudkowska, 2017). Not only it is officially recommended by Eurostat and the European Central Bank but has many users from all categories around the world (Eurostat, 2018; Buono and Ladiray 2017).

Following Eurostat guidelines (Eurostat, 2015) a pre-treatment of the series was running. Before the seasonal adjustment itself, a short graphical inspection was performed upon the series to reveal some basic characteristics. Next, the presence of seasonality is tested using the Seasonality tests tool. Next, the series was checked for outliers using the outlier detection tool. As Mirică et al. (2016) already pointed out, in the case of level shift outliers there is a need to cut the series, therefore, the series will be checked especially for this kind of outliers. If no such outliers are detected, no other specific adjustments will be performed on the time series.

For the seasonal adjustment process the calendar was defined in order to contain all the legal holidays in Romania at present: 1st and 2nd January, 24th January, Julian Easter and 
Easter related holidays, 1st May, 1st June, 15th August, 30th November, 1st December, Christmas and the second day of Christmas. For all these holidays the date they became a legal holiday was taken into consideration. In order to test the impact of the calendar on this time series, seasonal adjustment is performed both with calendar adjustment and without calendar adjustment. For the case when calendar adjustment was also performed, the Easter effect will also be checked.

Next, both TRAMO-SEATS and X-13 will be used as seasonal adjustment packages. For these tools the automatic procedure with the most complex specifications available namely RSA full and RSA5c respectively, will be used. This tool automatically chooses the ARIMA model and the decomposition method and corrects for outliers therefore, being very easy to use to better understand businesses affected by seasonality (Toma and Mirică, 2018). Two time-series spans will be tested in order to see which of these time spans provides best results, following the recommendations of Buono et al. (2018): 5 years and the entire series.

In order to assess the quality of these series, the overall quality indicator provided by JDemetra+ will be first and foremost considered. Also, residual seasonality indicators will be evaluated again following the recommendations of Buono et al. (2018). Additionally we will provide information for the AIC.

\section{Results and discussions}

Figure 1 displays monthly data on arrivals of tourists accommodated in the structure of tourists reception at national level between January 2010 and December 2018. As one can observe, there is obvious seasonality in this time series. Minimum levels are usually reached in January, except for 2012 and 2018 when the minimum level was reached in February. This is an important characteristic as it gives signals for outliers. Maximum levels are reached in august. Also, this time series presents an ascending trend and the variance increases slightly with the trend. Thus, a multiplicative model is more suitable for seasonally adjust this time series (UNSD, 2010).

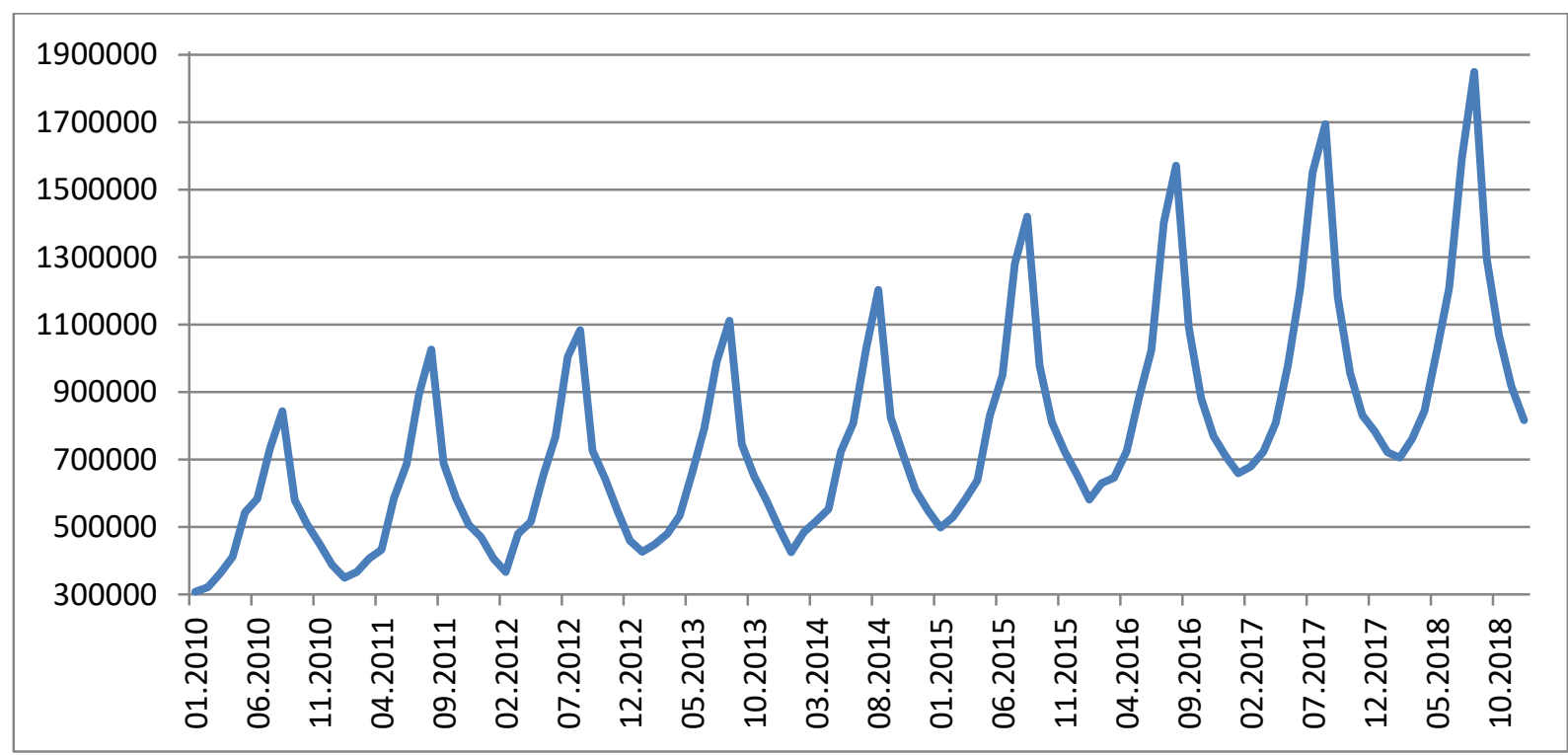

Figure 1. Monthly data on arrivals of tourists accommodated in the structure of tourists reception at national level between January 2010 and December 2018

Source: designed by the authors based on data from the National Institute of Statistics (TEMPO Database). 
Table 1 presents the results of the seasonality tests. As one can observe all the tests show that seasonality is present.

Table 1. Seasonality tests results, source: designed by the authors

Test

Auto-correlations at seasonal lags

Friedman (non parametric)

Kruskall-Wallis (non parametric)

Spectral peaks

Periodogram

Seasonal dummies

*P-value below $1 \%$
Value

$164.9501^{*}$

84.6538*

99.7394*

Very significant or significant peaks

128.6706*

$105.7044^{*}$

The results of the outlier detection tool show an additive outlier in February 2012. This was anticipated after the graphical inspection. As it is not the case of a level shift outlier, no specific prior adjustments will be performed on the time series.

Table 2 presents the results of the seasonal adjustment process for the entire series using TRAMO-SEATS and X13 with and without national calendar. As one can observe, similar results were obtained for both packages. The automatic procedure embedded in these packages log-transformed the series, as anticipated in the graphical inspection. Also, one should note that no Easter effect and no trading days effect can be observed. As the seasonal adjustment process requires parsimonious models, the calendar can be omitted for this time series. The seasonal adjustment procedure produced good quality results overall and all tests show that no seasonality is present.

Table 2. The results of the seasonal adjustment process for the entire series using TRAMOSEATS and X13 with and without national calendar

$\begin{array}{llll}\begin{array}{l}\text { TRAMO-SEATS } \\ \text { RSA full with } \\ \begin{array}{l}\text { National Calendar } \\ \text { Log-transformed }\end{array}\end{array} & \begin{array}{l}\text { X13 RSA5c with } \\ \text { National Calendar }\end{array} & \begin{array}{l}\text { TRAMO- } \\ \text { SEATS RSA } \\ \text { full }\end{array} & \text { X13 RSA5c } \\ \text { No } & \text { No } & \begin{array}{l}\text { Log- } \\ \text { transformed }\end{array} & \begin{array}{l}\text { Log- } \\ \text { transformed }\end{array} \\ \begin{array}{l}\text { No } \\ 1 \text { outlier }\end{array} & \text { No } & \begin{array}{l}\text { Not applicable } \\ \text { Not applicable }\end{array} & \begin{array}{l}\text { Not applicable } \\ \text { Not applicable }\end{array} \\ \text { no seasonality } & \text { no seasonality } & \text { no seasonality } & \text { no seasonality } \\ \text { present } & \text { present } & \text { present } & \text { present } \\ \text { Good } & \text { Good } & \text { Good } & \text { Good } \\ 2199 & 2199 & 2199 & 2199\end{array}$

Series

transformation

Easter Effect

Trading days effect

Outlier detected and

corrected

Residual seasonality

tests

Overall quality

AIC

2199

Source: Authors' own research.

Table 3 presents the results of the seasonal adjustment process for the five year time span using TRAMO-SEATS and X13 with and without national calendar. Similar results were obtained in all 4 cases: log-transformed series, no Easter effect, no trading days effect, no outliers, good overall quality including no seasonality present within residuals, similar AIC values. When comparing these results with those obtained for the entire series level, one can observe a much lower AIC. This indicates that a five years series span is more appropriate. 
Table 3. The results of the seasonal adjustment process for the 2014-2018 time-span using TRAMO-SEATS and X13 with and without national calendar

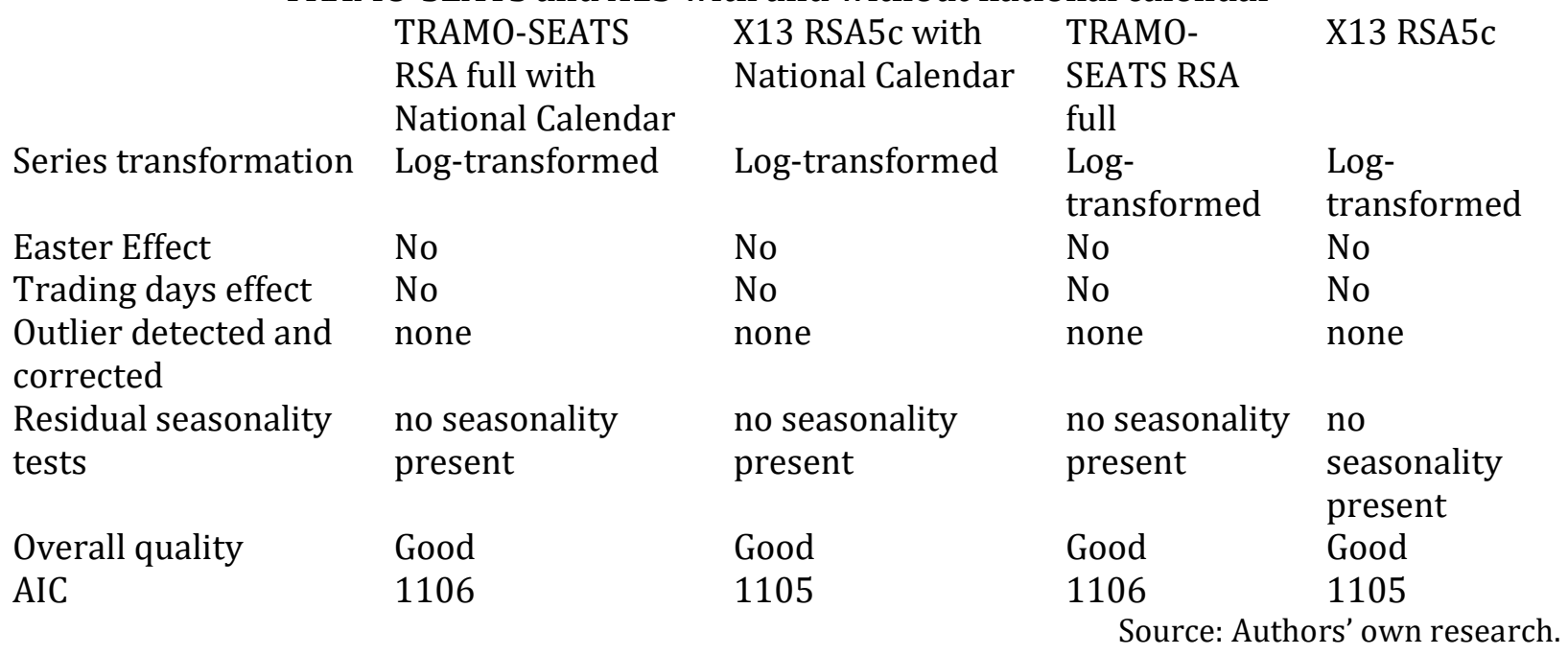

\section{Conclusion}

This paper aimed to explore the possibility to seasonally adjust tourism data for Romania in other to assess the quality that such series might have. Based on the literature review performed in the beginning, the arrivals of tourists accommodated in the structure of tourists reception at national level time series was chosen as an example.

As this study was meant to be exploratory, we used a simplified procedure to perform the seasonal adjustment process. As a consequence, the automatic procedure in JDemetra+ was employed. However, all the necessary tests prior seasonal adjustment (seasonality tests, outlier detection) were carried out.

The seasonal adjustment process showed promising results, as a good overall quality was obtained. No Easter and trading days effect were present, suggesting that the calendar might be omitted from the process. Also, significantly better results were obtained for the 5 years series span. However, the results are very similar for TRAMO-SEATS and X13 suggesting that further research needs to be performed in order to choose correctly between the two packages. In this respect, revisions must be taken into account as this is one of the most sensitive topics when presenting the results of the seasonally adjusted data (Kirchner, 2011).

Further research may address prediction modelling to reveal insights after the seasonal adjustment process. Moreover the present research can be extended to other monthly time series concerning tourism such as data on staying overnight in the establishments of touristic reception. Such data are also available in the TEMPO DATABASE of the National Institute of Statistics.

\section{References}

Baum, T. \& Hagen, L. (1999). Responses to seasonality: the experiences of peripheral destinations. International Journal of Tourism Research, 1 (5): 299-312.

Buono D, Infante E, Mazzi, G. L. (2018). Short versus long time series: An empirical analysis in Handbook on Seasonal Adjustment 2018 edition. Retrieved from: 
https://ec.europa.eu/eurostat/documents/3859598/8939616/KS-GQ-18-001-ENN.pdf .

Buono, D. \& Ladiray, D. (2017). JDemetra+ Java tool for seasonal adjustment. Retrieved from: https://www.slideshare.net/DarioBuonoPhDinEcono/jdemetra-java-tool-forseasonal-adjustment.

Butler R. W. (1994). Seasonality in Tourism: Issues and Problems. In A. V. Seaton (ed.) Tourism: the State of the Art. Chichester: Wiley \& Sons.

Butler, R. W. (2001). Seasonality in Tourism: Issues and Implications. In T. Baum \& S. Lundtorpe (Eds.). Seasonality in Tourism. Oxford: Pergamon.

Danubianu, M., Socaciu, T. \& Barila, A. (2009). SOME ASPECTS OF DATA WAREHOUSING IN TOURISM INDUSTRY. The Annals of The "Ștefan cel Mare" University Suceava. Fascicle of The Faculty of Economics and Public Administration, Volume 9, No.1(9).

De Cantis, S., Ferrante, M. \& Vaccina, F. (2011). Seasonal pattern and amplitude - A logical framework to analyse seasonality in tourism: An application to bed occupancy in Sicilian hotels. Tourism Economics. 17, pp. 655-675, doi: 10.5367/te.2011.0055.

European Committee of the Regions, (2017). Europe's leaders set out vision for sustainable tourism to drive growth and create jobs. Retrieved from:

https://cor.europa.eu/en/news/Pages/Europes-leaders-set-out-vision-forsustainable-tourism-to-drive-growth-and-create-jobs.aspx.

European Committee of the Regions, (2016). OPINION Tourism as a driving force for regional cooperation across the EU. Retrieved from:

https://cor.europa.eu/Documents/Migrated/Events/Tourism\%20as\%20a\%20drivi ng\%20force\%20for\%20regional\%20cooperation\%20across\%20the\%20EU.pdf. European Committee of the Regions, European Parliament, NECSTouR, European

Travel Commission, (2017). Open letter. Retrieved from:

https://cor.europa.eu/Documents/Migrated/Events/Revision\%20of\%20the\%20EU \%202010\%20Tourism\%20Strategy\%20-\%20ECWP\%202018\%20-

\%200pen\%20letter\%20to\%20EC\%20President\%20\%20Juncker.pdf.

Eurostat, (2015). ESS guidelines on seasonal adjustment, Manuals and guidelines, Luxembourg: Publications Office of the European Union, 2015 edition, ISSN 23150815.

Eurostat, (2017). Tourism statistics: Early adopters of big data?. Statistical Working papers, 2017 edition, doi:10.2785/202932 KS-TC-17-004-EN-C.

Eurostat, (2018). Seasonal Adjustment. Retrieved from: https://ec.europa.eu/eurostat/web/research-methodology/seasonal-adjustment

Grudkowska, S. (2015). JDemetra+ User Guide. Retrieved from: https://ec.europa.eu/eurostat/cros/system/files/jdemetra_user_guide.pdf.

Grudkowska, S. (2017). JDemetra+ User Guide Version 2.2. Retrieved from: https://ec.europa.eu/eurostat/cros/system/files/jdemetra_user_guide_version_2.2. pdf.

Hinch, T. D. \& Jackson, E. L. (2000). Leisure constraints research: its value as a framework for understanding tourism seasonality. Current Issues in Tourism, 3 (2): 87-106.

Hylleberg, S., ed (1992). Modelling Seasonality, Oxford University Press, Oxford.

Kirchner, R. (2011). ESS Guidelines on Seasonal Adjustment. Presentation held in Luxembourg, 15 November 2011. Retrieved from: 
https://ec.europa.eu/eurostat/cros/content/15-17-november-2011-demetraadvanced-users_en.

Kusnets, S. (1933). Seasonal Variations in Industry and Trade. New York: National Bureau of Economic Research.

Mirica, A., Andrei, T., Dascălu, E. D., Rădulescu, G. I. M., \& Glăvan, I. R. (2016). REVISION POLICY OF SEASONALLY ADJUSTED SERIES-CASE STUDY ON ROMANIAN QUARTERLY GDP. ECONOMIC COMPUTATION AND ECONOMIC CYBERNETICS STUDIES AND RESEARCH, 50(3), 45-62.

Panyik, E. \& Zaharia, M. (2014). A COMPARATIVE ANALYSIS OF FOREIGN TOURIST ARRIVALS IN PORTUGAL AND ROMANIA 2004-2014. Journal of tourism - studies and research in tourism, Issue 17.

Pegg, S., Patterson, I. \& Vila Gariddo, P. (2012). The impact of seasonality on tourism and hospitality operations in the alpine region of New South Wales, Australia. International Journal of Hospitality Management - INT J HOSP MANAG, 31, doi: 10.1016/j.ijhm.2011.09.001.

Rodrigues, P.M.M., \& Gouveia, P.M.D.C.B. (2004). An application of PAR models for tourism Forecasting. Tourism Economics, Vol 10, pp 281-303.

Shen, S., Li, G. \& Song, H. (2009). Effect of seasonality treatment on the forecasting performance of tourism demand models?. Tourism Economics, pp. 693-708.

Toma, I. E., \& Mirica, A. (2018). Using Statistical Data to Better Understand Business Environment-Case Study on Export and Import Data at County Level. Romanian Statistical Review, (2).

Toma, I. E., Mirica, A., \& PĂUNICĂ, M. (2018). Seasonal Adjustment of the Industrial Production Index for Romania-An Innovative Approach Using JDemetra+ 2.1. Romanian Statistical Review, (4).

UNSD, (2010). Seasonal Adjustment and Time Series Issues. Workshop on Manufacturing Statististics for ECLAC member states, Santiago.

Wöber, K.W. (2000). Standardizing City Tourism Statistics. Annals of Tourism, Research 27, 1, 51-68.

Yang, X., Pan, B., Evans, J. A., \& Lv, B. (2015). Forecasting Chinese tourist volume with search engine data. Tourism Management, 46, 386-397. 